\title{
СПЕЦИФИКА ИЗУЧЕНИЯ АУТЕНТИЧНЫХ ТЕКСТОВ НА УРОКАХ ПО РУССКОМУ ЯЗЫКУ КАК ИНОСТРАННОМУ. ПОЗНАНИЕ И УСВОЕНИЕ СОДЕРЖАНИЯ ТЕКСТОВ
}

\section{THE SPECIFICS OF STUDYING AUTHENTIC TEXTS IN RUSSIAN AS A FOREIGN LANGUAGE LESSONS. COGNITION AND ASSIMILATION OF THE CONTENT OF TEXTS}

Summary: The article is devoted to the process of studying authentic texts in classes in Russian as a foreign language, in particular, the study of artistic productions; the relevance of referring to such texts is substantiated. Recommendations are given on the choice of an authentic text that should correspond to the interests of students, as well as their life experience and level of speech training. The expediency of choosing the texts of modern writers in contrast to the works of classical literature is substantiated. Special attention is paid to the learning type of reading. Attention is drawn to the fact that it is more appropriate to carry out tasks in the form of a dialogue between the teacher and students. Tasks aimed at developing important speech skills are considered. Examples of pre-text, pre-text and post-text exercises are given that contribute to the development of such speech skills as independent work with a literary text, in particular, reading and correct understanding of the text, understanding unfamiliar vocabulary based on the language environment, using new lexical units in a situation of live communication, the ability to understand the general content of the text, as well as the meaning of its semantic parts, the ability to respond to the teacher's requests and create their own statements on a specific topic.

Keywords: authentic text, artistic text, speech communication, speech skills, learning tasks, communicative strategies, lexical material, pre-text tasks, pre-text tasks, post-text tasks.

\author{
Серебренникова Надежда Геннадиевна \\ К.филол.н., ФГБОУ ВО «Тамбовский государственный \\ университет имени Г.Р. Державина», г. Тамбов \\ Nadegda_korrespondensija@mail.ru
}

Аннотация: Статья посвящена процессу изучения аутентичных текстов на занятиях по русскому языку как иностранному, в частности, изучению художественных произведений; обосновывается актуальность обращения к подобным текстам. Приводятся рекомендации по выбору аутентичного текста, который должен соответствовать интересам обучающихся, а также их жизненному опыту и уровню речевой подготовки. Обосновывается целесообразность выбора текстов современных писателей в отличие от произведений классической литературы. Особое внимание уделяется изучающему виду чтения. Обращается внимание на то, что задания целесообразнее проводить в форме диалога преподавателя и обучающихся. Рассматриваются задания, направленные на развитие важных речевых навыков. Приводится примеры предтекстовых, притекстовых и послетекстовых упражнений, способствующих развитию таких речевых умений, как самостоятельная работа с художественным текстом, в частности, чтение и правильное понимание текста, понимание незнакомой лексики исходя из языкового окружения, использование новых лексических единиц в ситуации живого общения, умение понимать общее содержание текста, а также значение его смысловых частей, умение отвечать на вопросы преподавателя и создавать собственные высказывания на определенную тему.

Ключевые слова: аутентичный текст, художественный текст, речевое общение, речевые навыки, учебные задачи, коммуникативные стратегии, лексический материал, предтекстовые задания, притекстовые задания, послетекстовые задания.
$\mathrm{T}$ екст, который изучается на занятиях, представляет собой сложный феномен, т.к. является средством коммуникации и способом передачи сведений о традициях, культуре того или иного народа [1, с. 4; 5, с. 331]. Поэтому изучение аутентичных текстов, т.е. текстов, написанных носителями языка для носителей того же языка, представляется очень важным с точки зрения решения многих задач, которые необходимо поставить перед учащимися на занятиях по русскому языку как иностранному [4].

Студенты должны научиться речевому общению. «Современная методика преподавания русского языка как иностранного в качестве основной цели практического языкового курса выдвигает обучение речевому общению... Основная цель подчиняет и интегрирует учебные задачи, выстраивая определённую иерархию: значимость всех получаемых учащимися знаний о языке и культуре, а также формируемых у них речевых навыков и умений определяется в соответствии с тем, насколько они востребованы (или могут быть востребованы) в речевом общении изучающих русский язык» $[7$, с. 734735]. Учащиеся должны научиться воспринимать тексты в устной и письменной форме, которые были созданы носителями языка в условиях естественного общения [8, c. 29]. И для достижения поставленных целей необходимо и закономерно обращение к изучению аутентичных текстов. В условиях аудиторных занятий в качестве та- 
кого рода текстов естественным образом могут выступать художественные тексты [2; 3, с. 8]. В данном случае закономерно возникает вопрос: какие тексты нужно выбирать для чтения в условиях аудиторных занятий по русскому языку как иностранному? По этому поводу Н.В. Кулибина замечает: «Принципы отбора текстового материала определяются в соответствии с тем, какой цели мы хотим достичь, какого результата ожидаем. Так как в качестве основной цели работы над художественным текстом мы выбираем самостоятельное смысловое восприятие текста учащимся - понимание, то это обстоятельство заставляет нас особым образом подойти к вопросу отбора текстового материала: это должны быть тексты, которые потенциальный читатель хочет и может понять. Главным критерием отбора в этом случае является интерес учащегося, его вкусы, желания и потребности» [6, с. 100]. Действительно, не существует единой точки зрения на то, какие тексты можно изучать на занятиях с иностранными учащимися. Это могут быть, например, произведения русской классической литературы, но могут быть и произведения современных писателей. Более оправданным все же следует считать обращение к современным текстам, т.к. учащимся они гораздо понятнее не только с точки зрения содержащейся в них лексики (хотя и это может стать существенной трудностью), но и с точки зрения восприятия событий и персонажей в условиях реальной действительности, которая их окружает. Менталитет современных людей, живущих в разных странах, имеет много общего. Представить себе образ жизни современника, пусть даже живущего в другом государстве с совершенно иными культурными традициями, гораздо легче, чем постичь образ жизни людей 19 века. Поэтому при чтении произведений классической литературы иностранцами может возникнуть много трудностей, связанных с незнанием особенностей менталитета и культуры русского человека 19 века. Затруднение может быть связано и с языковыми особенностями, т.к. подобные произведения содержат много устаревшей, архаичной лексики, на понимание значения которой иностранным студентам нужно будет затратить много усилий при условии, что в дальнейшем они никак не будут использовать данную лексику в живом общении. Что же касается грамматических трудностей, то следует отбирать тексты таким образом, чтобы они содержали минимум незнакомого грамматического материала [7, с. 736-737].

Таким образом, текст, который изучается на уроке, должен быть интересен обучающимся, должен соответствовать их коммуникативным потребностям, их жизненному опыту, а также уровню их речевой подготовки $[9$, c. 100].

Процесс работы с текстом художественного произведения непосредственно соотносится с чтением как особым видом речевой деятельности. Цель чтения, по замечанию М.П. Чесноковой, - это «получение и переработка текстовой информации» [10, с.103]. Автор отмечает: «Обучение чтению облегчается по сравнению с обучением аудированию и говорению, так как читающий может выбирать для себя наиболее оптимальный темп... Постижение информации текста идет по ассоциации «форма - значение», а форма знака более чётко отображается в сознании по сравнению со значением» [10, с.103]. Это особенно справедливо, на наш взгляд, в отношении художественного текста.

Как правило, «принято выделять такие виды чтения, как просмотровое, поисковое, ознакомительное, изучающее» [10, с.109]. Как нам кажется, при изучении аутентичных текстов следует обращаться к изучающему чтению, т.к. в данном случае учащиеся читают текст внимательно, в довольно медленном темпе, кроме того, при таком виде чтения делается установка на дальнейшее использование встречающейся в тексте информации.

Обычно выделяют такие виды работы с текстом, как предтекстовые, притекстовые, а также послетекстовые задания.

В качестве предтекстовой работы могут быть использованы различные виды упражнений, но главная цель в данном случае - коммуникативная, и она состоит в том, чтобы заинтересовать студентов, вызвать у них желание ознакомиться с этим произведением. Предтекстовая работа должна вестись в форме диалога преподавателя и студентов, в ходе которого учащиеся могут получить необходимые сведения об авторе текста, краткую информацию о других произведениях писателя.

Предтекстовые упражнения также связаны с объяснением непонятной слов, с обучение тому, как можно использовать данную лексику в речи. Однако работа с новой лексикой не должна являться самоцелью, необходимо помнить, что данный этап направлен не только на то, чтобы помочь учащемуся преодолеть речевые трудности, но, в первую очередь, чтобы подготовить его к пониманию текста.

Притекстовый этап работы представляет собой вопросы и задания, направленные на читательскую деятельность студентов. Чтение текста в аудитории - это непосредственная подготовка обучающихся к данному виду деятельности, направленная на то, чтобы научить их использовать когнитивные стратегии.

Чтение может проходить без перевода и с переводом. Преподаватель должен стремиться к тому, чтобы текст был понят учащимися без участия родного языка, поэтому следует ограничивать обучающихся в стремлении переводить все незнакомые слова, нужно учить их умению понимать незнакомую лексику исходя из языкового окружения. 
После первого прочтения преподаватель может выяснить, понял ли обучающийся общий смысл текста. Как правило, на этом этапе достаточно задать 1-2 вопроса, которые касаются общего содержания. Во второй раз текст может быть прочитан по абзацам или по смысловым частям. На данном этапе задаются более конкретные вопросы. Можно, например, попросить студентов прочитать каждый из абзацев и сформулировать основное значение отрывка отдельным предложением.

Послетекстовые задания должны обеспечить успешность смысловой обработки информации. Например, это могут быть следующие виды заданий: учащимся предлагается сформулировать ответы на вопросы по содержанию текста; составить план текста, поставить в правильном порядке пункты плана; сформулировать основную мысль текста; выразить своё отношение к персонажам произведения.

Изучение аутентичных текстов, таким образом, очень эффективно при обучении русскому языку как иностранному. Чтение данного вида текстов положительно влияет на формирование словарного запаса, так как происходит естественное запоминание языковых конструкций. В ходе изучения текстов также происходит интенсивная тренировка практических навыков во всех видах речевой деятельности.

\section{ЛИТЕРАТУРА}

1. Агманова А.Е. Текст как основа моделирования межкультурного общения / А.Е. Агманова // Текст в системе обучения русскому языку и литературе: материалы международной научно-методической конференции / Отв. ред. Е.А. Журавлева. - Астана: Изд-во ИП «Дана», 2018. - 300 с

2. Барсегян К.М. Использование аутентичных материалов вне языковой среды (вьетнамские учащиеся, начальный этап) / К.М. Барсегян // Сборник материалов XVIII международной научно-практической конференции «Язык, куль-тура, менталитет: проблемы изучения в иностранной аудитории», РГПУ им. А.И. Герцена, Санкт-Петербург, 2019.

3. Барсукова-Сергеева 0.М. Читая сказки...: учеб. пособие / 0.М. Барсукова-Сергеева. - М.: Флинта: Наука, 2009. - 200 с.

4. Ковалева Н.А. Работа с художественным текстом на уроках РКИ (особенности восприятия) / Н.А. Ковалева, Н.Л. Вертунова // Цивилизация знаний: российские реалии. Материалы XVI Международной научной конференции (РосНОУ, ИНИОН РАН, ЦЭМИ РАН), апрель 2017. - М. - С. $269-274$.

5. Крючкова Л.С. Практическая методика обучения русскому языку как иностранному / Л.С. Крючкова. - М..: Флинта: Наука, 2012. - 480 с.

6. Кулибина Н.В. Зачем, что и как читать на уроке. Методическое пособие для преподавателей русского языка как иностранного / Н.В. Кулибина. - Златоуст, 2015. - 175 C.

7. Кулибина Н.В. Проблема обучения пониманию текстов на иностранном (русском) языке в свете общеевропейских компетенций владения языком / Н.В. Кулибина. - Foreign Language Teaching, Volume 40, Number 5, 2013, р. 733-739.

8. Лебедева М.Ю., Куваева, А.С. Синхронный онлайн-урок по РКИ как особая форма обучения в цифровой среде / М.Ю. Лебедева, А.С. Куваева // Русский язык за рубежом - N 2. - 2020. - C. 27-33.

9. Сарычева И.И. Использование аутентичных текстов в обучении иностранному языку студентов нелингвистических специальностей) / И.И. (арычева // Вестник науки и образования. - 2018 - N 12(48). - С. 100-103.

10. Чеснокова М.П. Методика преподавания русского языка как иностранного: учеб. пособие / М.П. Чеснокова. - 2 изд., перераб., - М.: МАДИ, 2015. - 132 с. 